\title{
O DESAFIO DA INCLUSÃO: BUSCANDO CAMINHOS ENTRE OS LIMITES E POSSIBILIDADES DA ESCOLA
}

\section{Andréa Fernandes Sá}

\section{RESUMO}

A escola deve ser considerada um espaço inclusivo, um espaço de todos e para todos. Espaço este, em que devemos buscar atender e entender a diversidade humana. Neste sentido, o presente artigo buscou mostrar, através dos estudos e reflexões realizados pelas professoras de Educação Especial de uma escola municipal de Campinas, quais ações, entendidas como ações didático-pedagógicas, que devem ser tomadas dentro e fora de sala de aula visando a promoção da inclusão de alunos com necessidades educacionais especiais.

\section{PALAVRAS-CHAVES}

Inclusão; Educação especial; Processo ensino-aprendizagem.

\section{THE CHALLENGE OF THE INCLUSIVE EDUCATION}

\section{ABSTRACT}

The school must be consider an inclusive place, a place that belongs to everybody, for everybody. Place where we must attend and understand the human diversity. By this way, the following article did show, trough studies and reflections made by the Special Education teachers from a municipal school from Campinas, which actions, understood as pedagogical-didactic actions, that must be taken inside and outside the classroom, searching the promotion of the inclusion of the students in need of special education.

\section{KEYWORDS}

Inclusion; Special education; Teaching-learning process.

\section{INTRODUÇÃO}

O último trimestre de 2004 foi particularmente enriquecedor, pois iniciei como docente na Rede Municipal de Educação de Campinas, com o privilégio de trabalhar na EMEF (Escola Municipal de Ensino Fundamental) Padre Francisco Silva. Assumi como professora substituta as aulas de História (que a professora anterior deixou para se efetivar na rede municipal), nas seguintes salas: $6^{\mathrm{a}} \mathrm{s}$ séries $\mathrm{A}$ e $\mathrm{B}, 7^{\mathrm{a}} \mathrm{S}$ séries $A$ e $B$ e $8^{a}$ série $B$, no período vespertino (das 13:00 às 19:00 hs.).

No início, estava totalmente fora da realidade desse novo universo escolar, digo novo, pois já leciono na Rede Estadual de Educação, desde 1998, como professora efetiva, mas nunca havia ministrado aulas na Rede Municipal. 


\section{EM BUSCA DA ESCOLA INCLUSIVA Grupo de Pesquisa em Ensino Superior}

A direção da escola, os professores, funcionários e alunos me acolheram com muito carinho, e estavam sempre prontos a responder minhas constantes dúvidas, indagações e dificuldades. Aos poucos, fui me adequando ao projeto pedagógico da escola, o qual logo pedi para a Orientadora Pedagógica, a fim de inserir-me na proposta da escola. Após a leitura, a Orientadora orientou-me quanto às minhas dúvidas (que não foram poucas!), pois a estrutura e o funcionamento da escola eram totalmente diferentes daqueles com as quais trabalhei até então, como por exemplo: aulas triplas (não duplas) e trimestres (ao invés de bimestres).

Foi com imensa alegria que fui convidada a participar como integrante e bolsista do Projeto “Escola Singular: Ações Plurais”, desenvolvido a partir de 2004, na escola, no qual os professores iniciaram como pesquisadores, com acompanhamento em reuniões semanais (todas as segundas-feiras), os chamados GT’s (Grupo de Trabalho), pelos professores-coordenadores Ana Maria Falcão de Aragão Sadalla e Guilherme do Val Toledo Prado. Este grupo foi formado por grande parte de professores da Unidade Escolar, interessados em desenvolver a proposta do projeto.

Iniciamos as discussões nos grupos coletivos (GT's) e nos grupos individuais (Relações interpessoais, Ações didático pedagógicas, Motivação discente, Motivação docente, Pensamento e ação docentes e Avaliação da aprendizagem.). Ingressei no subgrupo Interdisciplinaridade, formado por: Conceição Freire (Português), Edna Klein (Ciências), Giselda Deliza (substituta contínua), Maria Pinheiro (Português), e eu, Carmen Fernandez (História), escolhi fazer parte desse sub-grupo devido à afinidade com as participantes e por interessar-me pelo tema.

As reuniões do sub-grupo Interdisciplinaridade aconteciam às $5^{\mathrm{a}} \mathrm{s}$ feiras, após o horário das aulas (19:30 às 21:30), cada semana em um local diferente. Buscamos através da leitura e discussão de textos, integrar teoria e prática e a interdisciplinaridade, tendo como objetivo a qualificação do trabalho pedagógico e a melhoria do ensino na escola.

O professor, na medida em que lê, debate e troca experiências torna-se pesquisador sendo capaz de resolver ou pelo menos amenizar os problemas que enfrenta no cotidiano em sala de aula. Neste contexto, concordo com Garcia (2000, p. 21) ao afirmar que o professor,

Aprende a ver com outros olhos, a escutar o que antes não ouvia, observar com atenção o que antes não ouvia, a registrar o que observa e experimenta, a ler teoricamente a sua própria prática, a acreditar em sua capacidade profissional, na medida em que elabora estratégias metacognitivas e lingüísticas.

Como todo início é difícil, não foi diferente conosco, pois era preciso integrar teoria e prática, procurar relacionar o que líamos com a prática da sala de aula. Para isso, foram importantíssimas as 


\section{EM BUSCA DA ESCOLA INCLUSIVA Grupo de Pesquisa em Ensino Superior}

reuniões semanais em que cada integrante do sub-grupo interdisciplinaridade contribuía através das leituras sobre o tema e experiências vividas em sala de aula. Assim as idéias fluíam e todos participavam com entusiasmo e dedicação.

Quando ingressei na EMEF Padre Francisco Silva, no início do terceiro trimestre de 2004, optei em fazer uma avaliação diagnóstica junto aos alunos (por série) a fim de identificar quais conteúdos haviam assimilado.

Utilizei o livro didático de Montellato (2000), disponível na biblioteca da escola e escolhido pelos professores da disciplina de História, que, por sinal, considero muito bom, pois aborda a realidade atual para depois levar um mesmo fato, acontecimento, povos ou civilizações em outro tempo e espaço.

Percebi logo que, nesta primeira sondagem (avaliação diagnóstica) a maioria dos meus alunos, nestas três séries em que ministrava a disciplina (6 $6^{a}, 7^{a}$ e $\left.8^{a}\right)$, estavam com uma imensa defasagem em relação ao conteúdo tanto da série em que estavam, quanto das séries anteriores, pois devido à grande troca de professores de História, os alunos não tiveram uma continuidade de conteúdos. E, portanto, seria necessário retornar aos conteúdos anteriores, para que eu pudesse prosseguir.

A partir disso, reuni-me com a Orientadora Pedagógica da escola e com a Vice-diretora e expus meu dilema e meu medo de não conseguir realizar um trabalho de acordo com a proposta pedagógica da escola. Decidimos então, que seria feita uma revisão dos conteúdos anteriores, através de leituras, textos e interpretação e, somente depois, daríamos continuidade ao conteúdo da série. Os alunos entenderam a difícil situação. Tinham realmente que voltar em alguns conteúdos não trabalhados anteriormente e aceitaram prontamente minha proposta de trabalho (revisão).

Retomando o percurso de estudo realizado nos sub-grupos, o tema escolhido para ser trabalhado pelos membros do nosso sub-grupo foi “Trabalho infantil, Preconceito e Discriminação racial”. Em Português, a professora Maria Pinheiro, trabalhou com o tema trabalho infantil e escolha profissional (6 $6^{\mathrm{a}} \mathrm{s}$ e $7^{\mathrm{a}} \mathrm{s}$ séries). A professora Conceição Freire, também de Português, desenvolveu juntamente com o professor de Educação Artística, na 8a série B “O Navio Negreiro” (leitura, interpretação e desenhos). A professora Giselda Deliza, professora substituta continua, ajudou muito a dar seqüência ao andamento do projeto nas salas, quando alguns professores ausentavam-se. A professora Edna Klein, de Ciências, conseguiu adequar seu conteúdo e trabalhou com anemia falciforme.

Já em História, trabalhei em todas as séries, a questão do trabalho escravo desde a Idade Antiga até os dias atuais, mostrando sempre que ainda hoje persiste, no Brasil e no Mundo. Para exemplificar isso e contextualizar fiz referência à Constituição Brasileira (1988), à Declaração Universal dos Direitos do Homem e do Cidadão (1789) e ao Estatuto da Criança e do Adolescente. 


\section{EM BUSCA DA ESCOLA INCLUSIVA Grupo de Pesquisa em Ensino Superior}

Os alunos elaboraram cartazes, maquetes e poemas e se mostraram bastante receptivos com a proposta de trabalho, participando e reconhecendo as contribuições dos afrodescendentes em nosso país, bem como o preconceito que existe em relação aos mesmos, mostrados em seus trabalhos. Pude perceber nessa atividade que os alunos se sensibilizaram e se tornaram mais conscientes do seu papel junto à sociedade globalizada de hoje. Concordo com Gallo (1999, p. 36) quando diz que

De nossa criatividade e de nossa ação política e capacidade de influência dependerá o delineamento de um processo educativo e de uma sociedade em que o controle se exerça de forma mais diluída e também mais intensa, dando-nos apenas uma ilusão de autonomia, ou então de uma educação e uma sociedade em que a autonomia seja um fato, numa realidade mais solidária e mais democrática.

Do meu ponto de vista, a equipe escolar foi de fundamental importância para o desenvolvimento desse projeto, pois abriu todos os espaços solicitados para reuniões e discussões, ajudando a inserir os professores iniciantes como eu, dando-nos total liberdade para elaborar aulas (com um novo planejamento), avaliações, utilização de material didático.

Acredito que pude contribuir com as minhas atividades garantindo à aprendizagem de habilidades e conceitos básicos para a vida em sociedade que, hoje, exige do cidadão uma série de competências e tornando-o consciente de seu papel e de sua função na sociedade.

Pude também resgatar a confiança de meus alunos e incentivá-los para que, se coloquem como seres pensantes, produtores de idéias e capazes de obterem sucesso em seu percurso escolar e em suas vidas.

Tenho certeza que, sem o apoio da FAPESP e da professora-coordenadora do GT, Ana Maria Falcão de Aragão Sadalla que nos direcionou e nos motivou em nosso objetivo de trabalharmos interdisciplinarmente, orientando-nos e dando-nos embasamento teórico para conseguir tornar nosso projeto uma realidade, não teria condições de aplicabilidade em sala de aula e do sucesso obtido pelo subgrupo na Unidade Escolar.

Esclareço que, quanto ao cronograma da próxima etapa de pesquisa, dependerá da atribuição de aulas em 2005, quando não sei se terei a oportunidade de continuidade do projeto de pesquisa nessa escola. Ao pensar nisso sinto-me triste e frustrada, mas, com certeza, o aprendizado com as leituras e pesquisas somente vieram somar em minha formação e tornar-me uma profissional com uma visão dinâmica e aberta a repensar novas práticas pedagógicas. Tenho certeza também, que sem o incentivo e apoio da FAPESP não teria a oportunidade iniciar nesse projeto de pesquisa.

(C) ETD - Educação Temática Digital, Campinas SP, v.7 , n. esp., p.127-131, jun. 2006 - ISSN: 1676-2592. 


\section{REFERÊNCIAS}

GALLO, S. Transversalidade e educação: pensando uma educação não-disciplinar. In: ALVES, N; GARCIA, R. (Orgs.). O Sentido da escola. Rio de Janeiro: DP\&A, 1999. p.36-37.

GARCIA, R. L. A formação de professores alfabetizados: reflexões sobre a prática São Paulo: Cortez, 1996. p. 21 - In: Carvalho, Avaliar com os pés no chão da escola. Recife: Ed. Univ. da UFPE, 2000. p.50.

MONTELLATO Andréa. História temática: diversidade cultural e conflitos. São Paulo: Ed. Scipione, 2000.

ANDRÉA FERNANDES SÁ

Psicopedagoga.

Professora de Educação Especial da

EMEF Padre Francisco Silva.

e-mail: deasa@uol.com.br 